\title{
Two electrosurgical endo-knives for endoscopic submucosal dissection of colorectal superficial neoplasms: a prospective randomized study
}

\section{(๑) $\odot \ominus$}

\author{
Authors \\ Institutions \\ 1 Department of Gastroenterology and Hepatology, \\ Okayama University Graduate School of Medicine, \\ Okayama, Japan \\ 2 Division of Endoscopy, Okayama University Graduate \\ School of Medicine, Okayama, Japan \\ 3 Center for Innovative Clinical Medicine, Okayama \\ University Graduate School of Medicine, Okayama, \\ Japan
}

Yuusaku Sugihara ${ }^{1}$, Keita Harada ${ }^{2}$, Yoshiro Kawahara ${ }^{2}$, Daisuke Takei ${ }^{2}$, Shiho Takashima ${ }^{1}$, Toshihiro Inokuchi ${ }^{1}$, Asuka Nakarai ${ }^{1}$, Masahiro Takahara', Kenji Kuwaki ${ }^{3}$, Sakiko Hiraoka', Hiroyuki Okada ${ }^{1}$

submitted 6.10.2016

accepted after revision 2.5.2017

\author{
Bibliography \\ DOI https://doi.org/10.1055/s-0043-111792 | \\ Endoscopy International Open 2017; 05: E729-E735 \\ (c) Georg Thieme Verlag KG Stuttgart · New York \\ ISSN 2364-3722
}

Corresponding author

Yuusaku Sugihara, MD, PhD, Department of

Gastroenterology and Hepatology, Okayama University

Graduate School of Medicine, Dentistry and Pharmaceutical

Sciences, 2-5-1 Shikata-cho, Kita-ku, Okayama, Japan 700-

8558

Fax: +81-86-225-5991

y.sugi117@gmail.com

\section{ABSTRACT}

Background and study aims Few studies have directly compared endo-knives for endoscopic submucosal dissec- tion (ESD) in humans. We compared the performances of the Mucosectom2 and SB knife Jr.

Patients and methods Two trainee endoscopists performed ESD of 36 lesions in this prospective, randomized controlled trial. Mucosal incision with a 1.5 -mm Dual knife and submucosal dissection using the Mucosectom2 were performed in 1 group. Mucosal incision with a $1.5-\mathrm{mm}$ Dual knife and submucosal dissection with a SB knife Jr. were performed in the other group. The primary outcome was the ESD procedure time. Secondary outcomes were total procedure time, self-completion rates, and adverse events.

Results ESD time in Mucosectom2 patients was not significantly shorter than in SB knife Jr. patients $(57 \pm 32$ min vs. $61 \pm 44 \mathrm{~min}$, respectively; $P=0.94)$. Total procedure time in Mucosectom2 patients was not significantly shorter than in SB knife Jr. patients $(81 \pm 42$ min vs. $82 \pm 51 \mathrm{~min}$, respectively; $P=0.85)$. The trainee self-completion rate was slightly higher in SB knife Jr. patients than in Mucosectom2 patients, although the difference was not significant (94\% vs. $100 \%$, respectively; $P=0.959$ ). Fewer hemostatic procedures using the Coagrasper were performed in Mucosectom2 patients than in SB knife Jr. patients, although the difference was not significant ( 0.62 vs. 0.7 , respectively; $P=$ 0.432).

Conclusions Mucosectom2 and SB knife Jr. did not significantly differ in performance for colorectal ESD to safely and reliably enhance ESD. Knife selection is not as important for learning colorectal ESD as patient- and lesion-related factors.

\section{Introduction}

Endoscopic submucosal dissection (ESD) is one of the standard treatments for large upper gastrointestinal superficial neoplasms in Japan because of its high en bloc resection (resection of the entire tumor in 1 piece) rate [1,2]. There have been some reports on ESD, a standard therapy for superficial colorectal neoplasms [3, 4], In addition, ESD has greater long-term benefit than conventional endoscopic mucosal resection $[5,6]$. However, ESD is time consuming, has technical difficulty, and is related to a higher incidence of complications, perforation, or bleeding. In general, the operator can accomplish colonic ESD using a single device on his or her own in almost all cases. However, in difficult situations, such as fibrosis or paradoxical movement of colonoscopy, an operator often uses more knives as secondary devices to safely perform colonic ESD. We thought 
that if an operator used the needle-type knife as the primary device they might use another type of knife, such as a blade or scissors type, in technically difficult cases.

The Mucosectom2 knife (Pentax Medical, HOYA Co., Tokyo, Japan) $[7,8]$ is designed specifically for submucosal dissection. It is composed of a non-conducting, rotatable plastic shaft and a $2.5-\mathrm{mm}$ cutting wire located at the side of the plastic shaft. The long cutting wire allows rapid dissection, while the nonconducting plastic shaft avoids inadvertent injury to the muscle layer. The SB knife Jr. (Sumitomo Bakelite Co., Ltd., Tokyo, Japan) was developed as a small scissor forceps for colorectal ESD [9]. This device is a grasping forcep that uses a monopole and is fitted $0.8 \mathrm{~mm}$ from the tips of the blades to keep the depth safe. The knives have superior rotation to allow the tips to be set in suitable positions [9]. These knives are quite different in character from a needle-type knife, such as the Dual knife, and they may allow us to perform ESD faster and more easily than with the needle-type knife.

Various devices are currently being developed to facilitate safe ESD. However, no studies to date have directly compared these devices for treatment of colonic tumors. Comparative studies of ESD devices are essential for optimizing colonic ESD, and they could provide useful information for achieving more effective ESD in the future. The aim of this study was to compare the performances of different types of knives: the blade type, represented by the Mucosectom2, and the scissors type, represented by the SB knife Jr., for dissection and safe colorectal ESD when used by trainee endoscopists.

\section{Patients and methods}

\section{Patients}

This study was designed as a prospective, randomized controlled trial and was conducted in the endoscopy unit at the Okayama University Graduate School of Medicine, Japan between May 2014 and September 2015. All study participants gave informed consent. The local ethics review committee granted ethical approval as approval number 2020, and the study was registered in the University Hospital Medical Network Clinical Trials Registry (UMIN-CTR) as number UMIN 000015762.

The inclusion criteria were: (1) tumor diagnosed with colonoscopy before ESD; (2) lesions of 20-50 mm in diameter; (3) colorectal intramucosal or minutes-invaded $(\mathrm{SM}<1000 \mu \mathrm{m})$ cancer; or (4) no lymph node or distant metastasis. Patients were excluded if they had: (1) non-correctable coagulopathy; (2) severe organ failure; (3) a comorbidity requiring continuous antithrombotic medication; or (4) procedure time longer than $180 \mathrm{~min}$. Several cases of colorectal ESD required an unexpectedly long procedure. In these cases, factors that do not relate to the differing capabilities of the device, such as strong fibrosis (tumor factors) and poor operability of colonoscopy (patient factors), will have a greater effect on the procedure time than device-specific factors. Therefore, to make the difference between the devices more noticeable, we considered it necessary to exclude cases that took considerably longer than a certain time. The reason for adopting a limit of 180 minutes was that

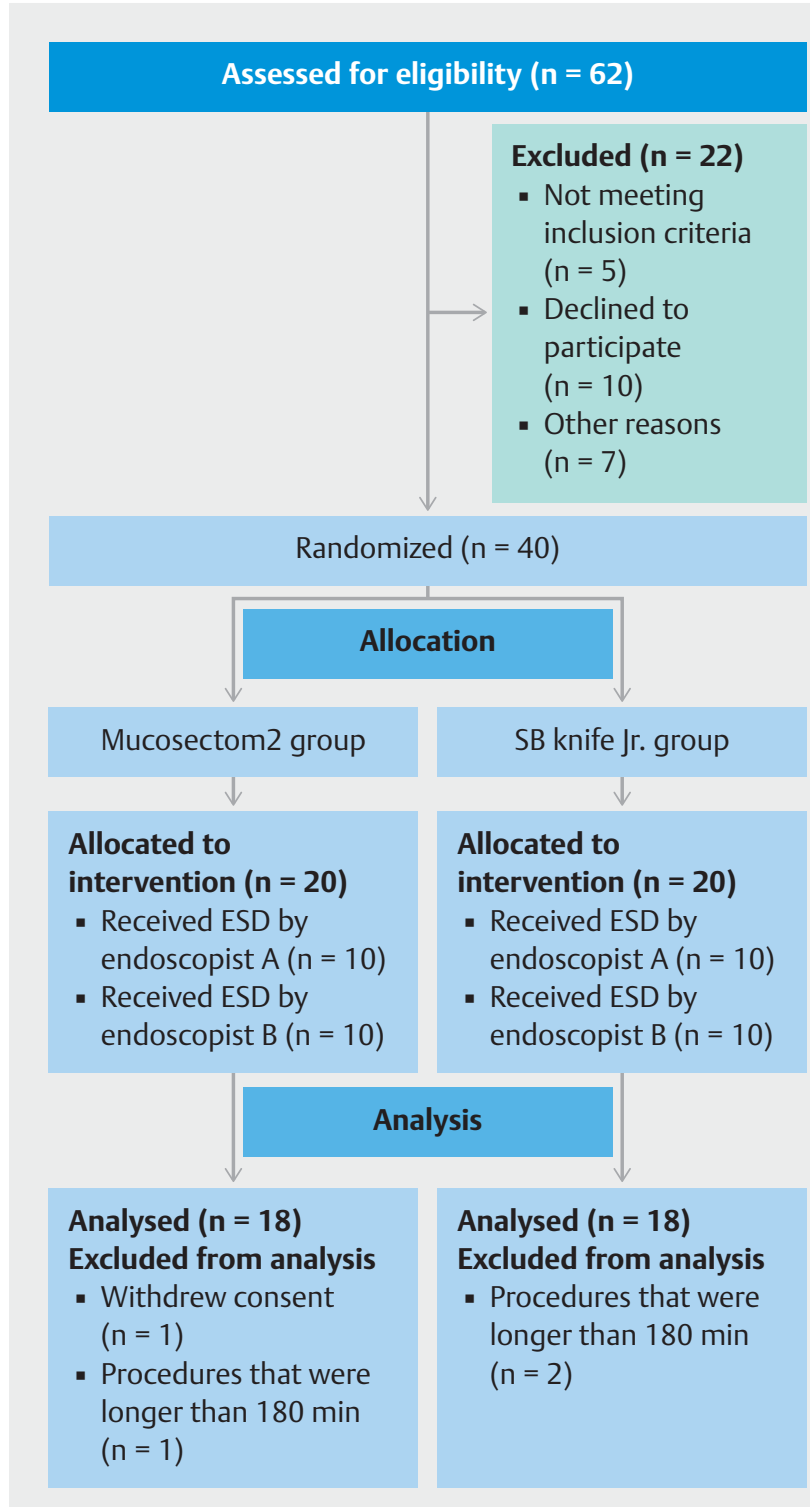

- Fig. 1 Flowchart for patient enrollment.

these cases represented the bottom $10 \%$ of colonic ESD cases in our hospital. Complication increases significantly when the procedures last longer than 180 minutes, based on experience in our hospital.

The participants were randomly assigned to treatment groups following simple randomization procedures. The randomization table was prepared using Excel 2007 (Microsoft Corporation, Redmond, WA, USA). The participants were allocated according to endoscopist (either Y.S. or D.T.). After stratification, participants were randomly assigned to the Mucosectom2 group or the SB knife Jr. group. Endoscopists were blinded to the sequence until treatments were assigned. However, when ESD is being performed, it is clearly not feasible to blind the endoscopist to their treatment allocation. 
- Table 1 Patient characteristics and histological results.

\begin{tabular}{|c|c|c|}
\hline & $\begin{array}{l}\text { Mucosectom2 } \\
\text { group }\end{array}$ & $\begin{array}{l}\text { SB knife Jr. } \\
\text { group }\end{array}$ \\
\hline & 16 & 20 \\
\hline Gender ( $n$ ) Male/female & $12 / 4$ & $8 / 12$ \\
\hline Age (years) Mean (range) & $72.3(58-85)$ & $67.5(49-87)$ \\
\hline \multicolumn{3}{|l|}{ Location } \\
\hline - Colon & 15 & 13 \\
\hline - Rectum & 1 & 7 \\
\hline $\begin{array}{l}\text { Estimated tumor size } \\
\text { (mm, range) }\end{array}$ & $29.8(18-45)$ & $35.2(18-55)$ \\
\hline $\begin{array}{l}\text { Estimated specimen size } \\
\text { (mm, range) }\end{array}$ & $34(20-50)$ & $39.2(23-60)$ \\
\hline \multicolumn{3}{|l|}{ Tumor type } \\
\hline - Protruded or LST-G & 10 & 18 \\
\hline . LST-NG & 6 & 2 \\
\hline \multicolumn{3}{|c|}{ Histologic diagnoses after ESD } \\
\hline - Mucosal cancer & 1 & 6 \\
\hline - Submucosal cancer & 3 & 1 \\
\hline - adenoma low grade & 8 & 9 \\
\hline - adenoma high grade & 3 & 2 \\
\hline - SSA/P & 1 & 2 \\
\hline \multicolumn{3}{|c|}{$\begin{array}{l}\text { ESD, endoscopic submucosal dissection; LST-G, laterally spreading tumor- } \\
\text { granular; LST-NG, laterally spreading tumor non-granular; SSA/P, sessile } \\
\text { serrated adenoma/polyp }\end{array}$} \\
\hline
\end{tabular}

\section{General setting of ESD}

ESD was performed under intravenous sedation using midazolam colonoscopy with a water jet function and a distal attachment cap (Olympus Co., Tokyo, Japan) for all procedures. Tumor outlines were delineated by chromoendoscopy with indigocarmin or narrow-band imaging. ESD was conducted using a Dual knife and Mucosectom2 or SB knife Jr. A Coagrasper (FD410LR; Olympus Co., Tokyo, Japan) was also used to stop bleeding. A coagrasper was the only tool used to treat bleeding in this study. A VIO electrosurgical generator (VIO 300D; ERBE, Tübingen, Q5 Germany) was used for all ESD procedures. The settings for each knife were as follows: Dual knives used Endocut I mode Effect 1, duration 3, interval 3 for marginal incision. The Mucosectom2 used Endo-cut I mode Effect 1, duration 3, interval 3 Swift coagulation Effect 340 W. The SB knife Jr. used Endo-cut I mode Effect 1, duration 3, interval 3 Swift coagulation Effect $340 \mathrm{~W}$. The Coagrasper used soft-coagulation mode Effect $580 \mathrm{~W}$ for haemostasis.

All procedures were initiated by 1 of 2 endoscopists (Y.S.; endoscopist A and D.T.; endoscopist B), who had performed fewer than 20 colonic ESDs and 50-70 gastric ESDs. A senior endoscopist (K.H.) provided verbal advice only, mainly to avoid adverse events (AEs) and to ensure that the correct process for

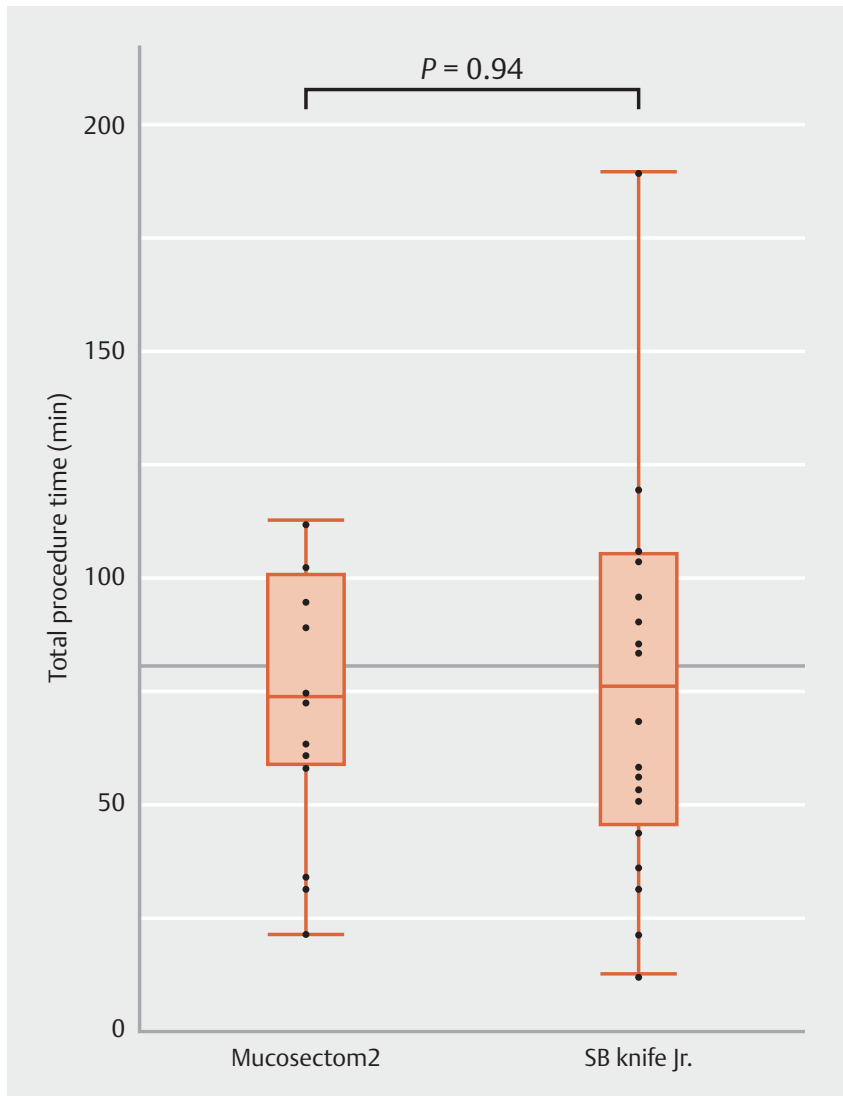

- Fig. 2 Submucosal dissection time in the Mucosectom2 group was not significantly shorter than that in the SB knife Jr. group ( $57 \pm 32 \mathrm{~min}$ vs. $61 \pm 44 \mathrm{~min}$., respectively; $P=0.94$ ).

ESD was followed. In our study, we did not include the time when the trainee interrupted the ESD procedure to receive verbal advice from a senior doctor. All lesions were resected using a similar process, as follows: In step 1 , a circular mucosal incision was made. In step 2, submucosal dissection of the whole submucosa was performed. The total procedure time was calculated by adding the time it took to perform steps 1 and 2 . Step 2 represented submucosal dissection time. The times required for exchanging catheters, controlling bleeding, and washing coagulum off the needle knife were included. Procedures completed by the trainee endoscopists alone were considered to be "self-completed." In certain circumstances, the procedures were completed by the senior endoscopist and were considered to be "non-self-completed." After ESD, histologic assessment of resected specimens was performed.

\section{Endo-Knives}

The Mucosectom2 was developed by Kawahara et al. [7, 8] and is composed of a rotatable, non-conducting plastic shaft and a 2.5-mm cutting wire located at the side of the plastic shaft. The SB knife Jr. (Sumitomo Bakelite) was developed as a small scissor forceps for colorectal ESD [9].

In the Mucosectom2 group, the mucosal incision was made using a 1.5-mm Dual knife, and submucosal dissection was performed using a Mucosectom2 knife. In the SB knife Jr. group, 


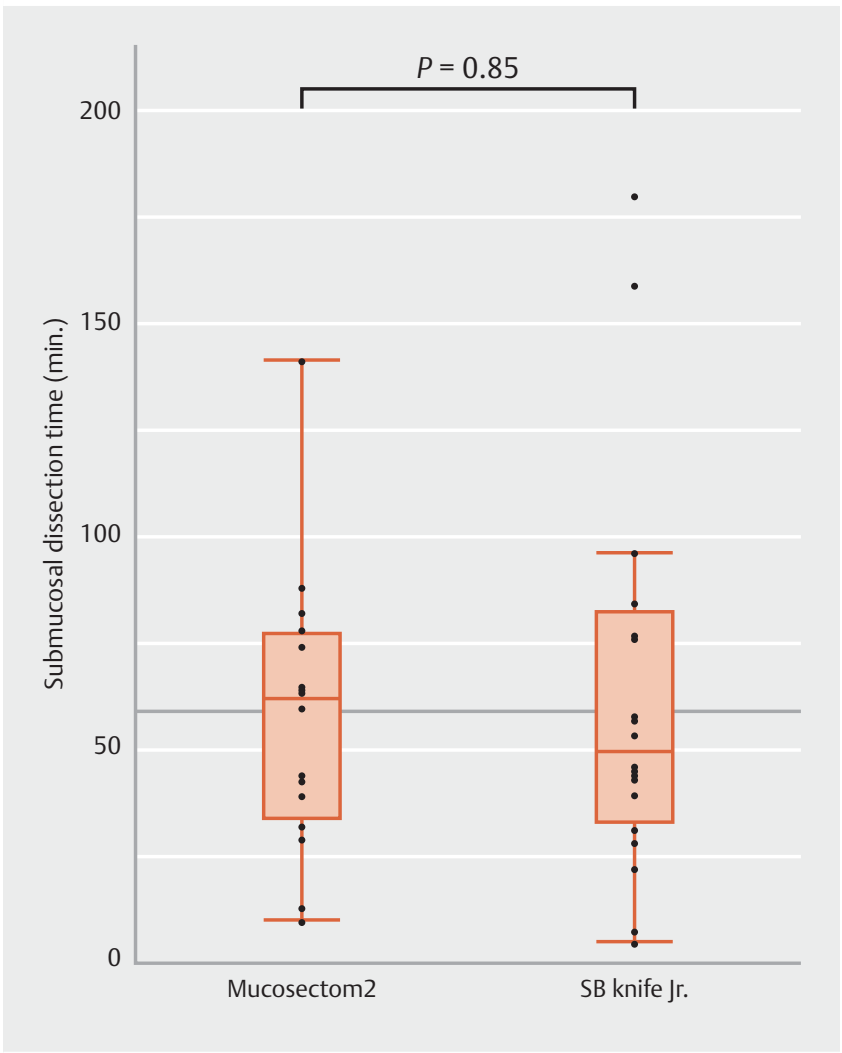

- Fig. 3 Total procedure time in the Mucosectom2 group was not significantly shorter than that in the SB knife Jr. group $(81 \pm 42 \mathrm{~min}$. vs. $82 \pm 51 \mathrm{~min}$, respectively; $P=0.85$ ). the mucosal incision was made using a 1.5-mm Dual knife, and submucosal dissection was performed using a SB knife Jr.

In both groups, $0.4 \%$ hyaluronate sodium solution (MucoUp; Johnson \& Johnson K.K., Tokyo, Japan) was injected into the submucosa using a 23-gauge endoscopic injection needle (Top Corporation, Tokyo, Japan) to elevate the lesion.

\section{End points and subgroup analyses}

The primary outcome was procedure time required for submucosal dissection. The secondary outcomes were total procedure time, self-completion rates,

AEs, number of times that hemostatic therapies such as the Coagrasper were used, en bloc resection rate, and complete resection rate. In our study, we defined perforation as follows: perforation was identified during the procedure visually, and it was diagnosed by presence of free air on a simple abdominal Xray scan.

\section{Statistical analysis}

Sample size was calculated based on initial results for colorectal ESD in our institution. We hypothesised that the mean procedure time for colorectal ESD using the Mucosectom2 knife would be $60 \pm 40 \mathrm{~min}$ and using the SB knife Jr. it would be 100 $\pm 40 \mathrm{~min}$. We planned to use a 2 -sided test to test for a significant between-groups difference, with a significance level of 0.05 and a power of $80 \%$. Seventeen patients were required in

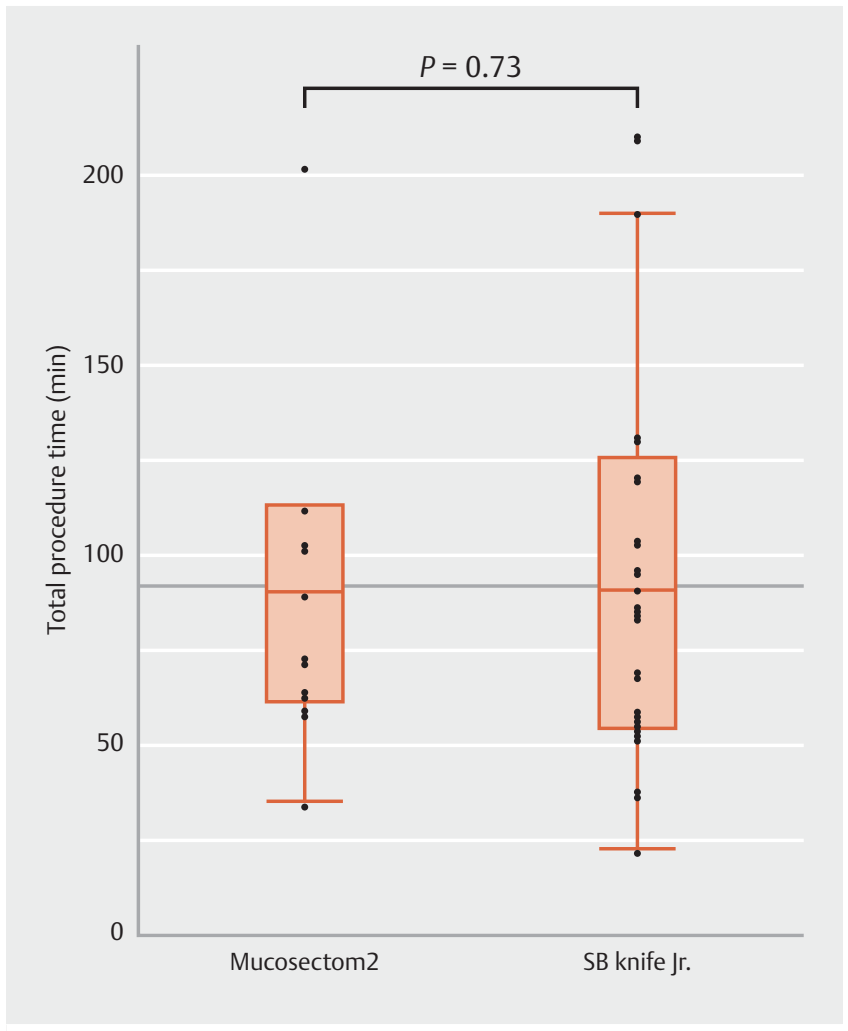

- Fig. 4 Prespecified subgroup analyses of total procedure time. Total procedure time was not significantly different in both groups by endoscopist A ( $94 \pm 47$ min. vs. $90 \pm 51$ min., respectively; $P=$ 0.73).

each group to detect a significant difference. Because individuals might drop out of the study, we decided to include 20 cases in each group. The results of the current study, such as procedure time, were expressed as mean \pm standard deviation. Continuous variables were compared using Student's $t$-tests. Categorical variables were compared using X2-tests or Fisher's exact tests, as appropriate. The significance level was set at $P<$ 0.05 . Statistical analysis was performed using the JMP 10.0 software package for Windows (SAS Institute, Cary, North Carolina, USA).

\section{Results}

\section{Patient characteristics}

Sixty-two patients who underwent colonoscopy before an ESD by the endoscopist A or B were assessed for eligibility, and of them, 22 patients were excluded because the lesions did not meet the inclusion criteria $(n=5)$, the individual declined to participate $(n=10)$, or other reasons $(n=7)$. Forty patients with a total of 40 lesions were enrolled in this study between March 2015 and June 2016. Of them, 20 were assigned to the Mucosectom 2 group and 20 to the SB knife Jr. group. After randomization, 1 patient withdrew consent and 3 patients had procedures that were longer than $180 \mathrm{~min}$. A total of 36 lesions in 36 patients were therefore analyzed ( $>$ Fig. 1 ). As we accumulated cases through randomization, there were no differen- 


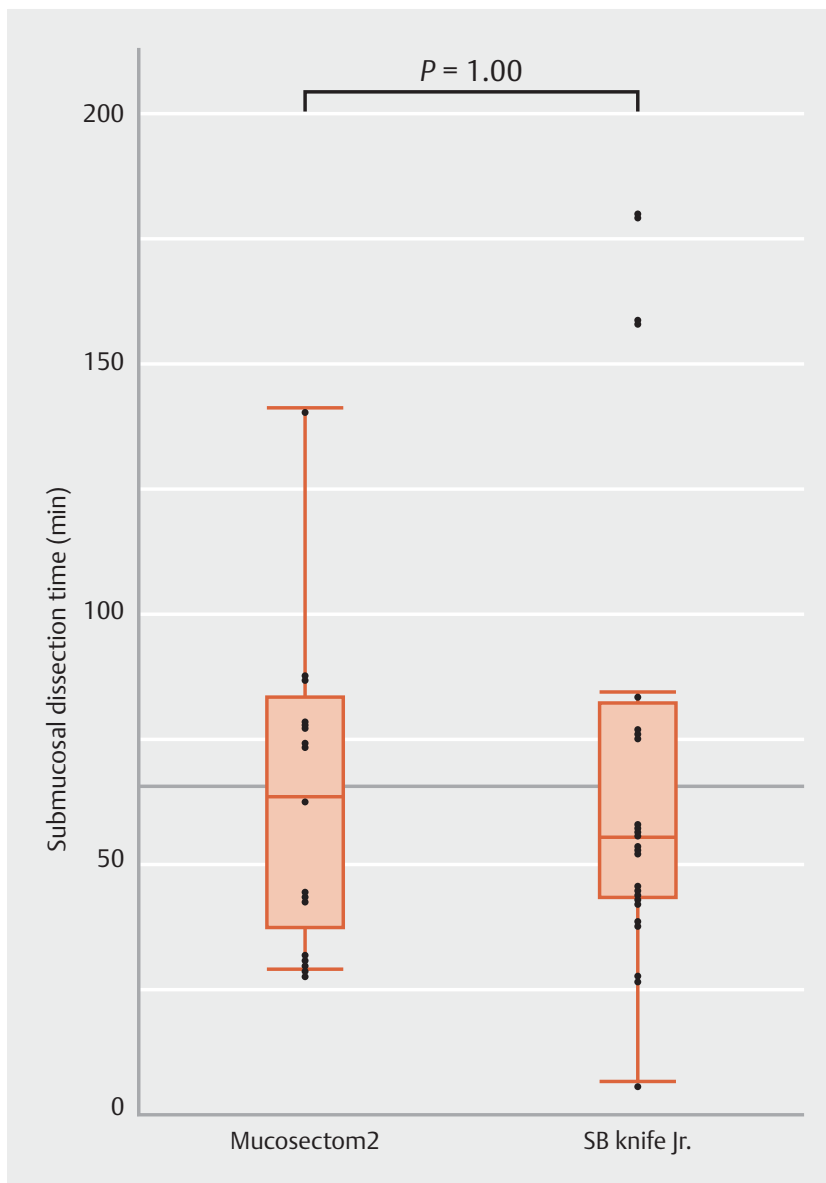

- Fig. 5 Submucosal dissection time was not significantly different in both groups by endoscopist A $(65 \pm 35 \mathrm{~min}$. vs. $67 \pm 44 \mathrm{~min}$., respectively; $P=1.00$ ).

ces in the other baseline patient characteristics or histologic results after ESD between the 2 study groups ( $\triangleright$ Table 1 ).

\section{Submucosal dissection and total procedure time}

There were no differences in submucosal dissection time between the Mucosectom2 group and the SB knife Jr. group (57 \pm 32 min. vs. $61 \pm 44$ min., respectively; $95 \% \mathrm{Cl}$ : $-31.50-33.12$, $P=0.94$; Fig. 2). In addition, there were no differences in total procedure time between the Mucosectom 2 group and the SB knife Jr. group ( $81 \pm 42 \mathrm{~min}$. vs. $82 \pm 51 \mathrm{~min}$., respectively; $95 \%$ $\mathrm{Cl}$ - $23.15-30.90, P=0.85$; $>$ Fig. 3 ).

For endoscopist $A$, there were no differences in total procedure time and submucosal dissection time in the Mucosectom2 group and the SB knife Jr. group. $(94 \pm 47$ min. vs. $90 \pm 51$ min., respectively; $95 \% \mathrm{Cl}:-46.92-39.28, P=0.73 ; 65 \pm 35 \mathrm{~min}$. vs. $67 \pm 44$ min., respectively; $95 \% \mathrm{Cl}:-34.30-37.74, P=1.00)$. For endoscopist $\mathrm{B}$, there were no differences in total procedure time and submucosal dissection time in the Mucosectom2 group and in the SB knife Jr. group. $(64 \pm 28 \mathrm{~min}$. vs. $48 \pm 40$ min., respectively; $95 \% \mathrm{Cl}:-62.60-30.77, P=0.57 ; 47 \pm 27$ min. vs. $38 \pm 39$ min., respectively; $95 \% \mathrm{Cl}:-54.77-36.63, P=$ 0.63; Fig. 4-7).

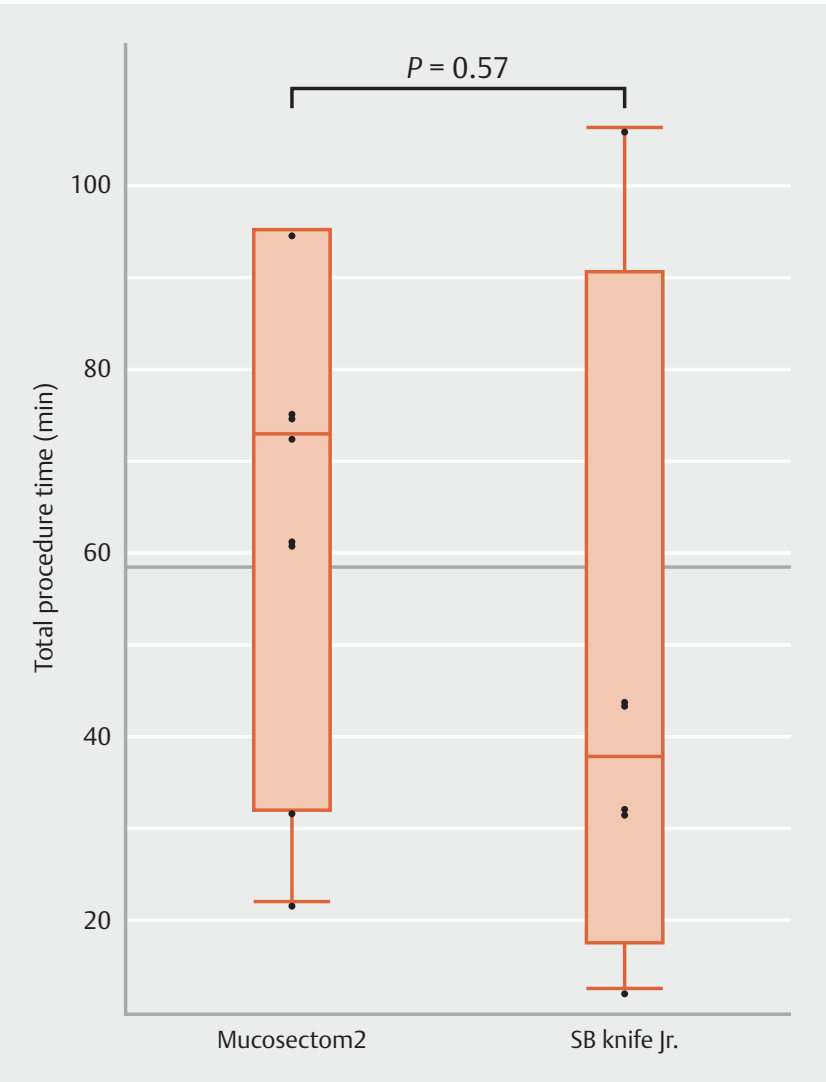

- Fig. 6 Total procedure time was not significantly different in both groups by endoscopist B $(64 \pm 28 \mathrm{~min}$. vs. $48 \pm 40 \mathrm{~min}$., respectively; $P=0.57$ ).

\section{Other secondary endpoints}

Results of the other secondary endpoints evaluated in this study are shown in $>$ Table 2 . En bloc and complete resection rates were sufficiently high in both groups ( $94 \%$ in the Mucosectom 2 group and $95 \%$ in the SB knife Jr. group) and were not significantly different. The self-completion rate was slightly higher in the SB knife Jr. group compared with that in the Mucosectom 2 group, although the difference was not significant ( $95 \%$ vs. $100 \%$, respectively; $P=0.959$ ). The main reason for failure of self-completion was injury to the muscularis propria. In terms of AEs, 1 perforation occurred in each group, which was successfully treated by endoscopic clipping. No postoperative bleeding occurred in either group. Slightly fewer hemostatic procedures using the Coagrasper were performed in the Mucosectom2 group than in the SB knife Jr. group, although the difference was not significant ( 0.62 vs. 0.7 , respectively; $P=0.432$ ).

\section{Discussion}

A variety of knives have been developed to improve the safety and reduce the procedure time of endoscopic surgery. A single-arm study reported the high performances of the Mucosectom 2 and the SB knife Jr. with favorable en bloc resection rates of $95 \%-100 \%$ and perforation rates of $0 \%-6.9 \%[7,8,9]$. We 


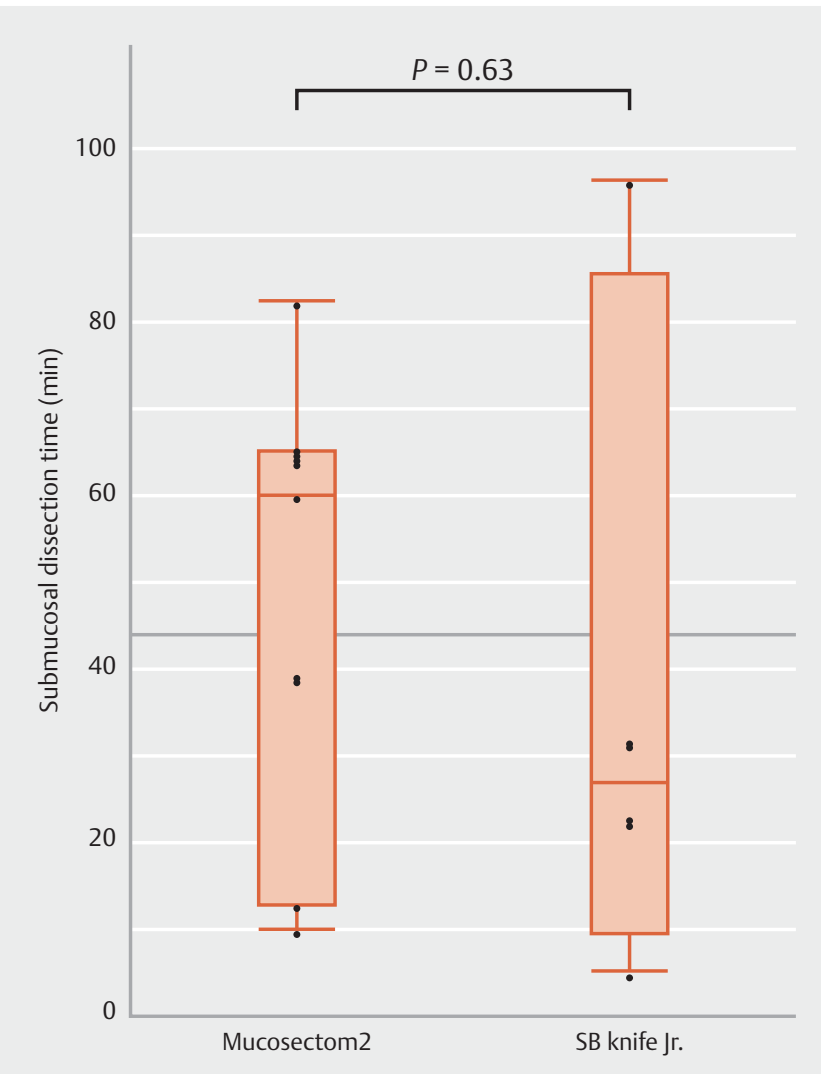

- Fig. 7 Submucosal dissection time was not significantly different in both groups by endoscopist B $(47 \pm 27 \mathrm{~min}$. vs. $38 \pm 39 \mathrm{~min}$., respectively; $P=0.63$ ).

think that standardization of the setting for ESD thus requires performances of knives to be compared. Because there have been few comparative clinical studies [10], we therefore conducted a randomized, prospective trial to compare performance of 2 different knives for treatment of colorectal cancer in a clinical setting.

We selected the Mucosectom2 and the SB knife Jr. from among the various endo-knives because these knives have sim- ilar characteristics and are different from needle-type knives. Both knives are designed specifically for submucosal dissection and do not have a water-out function. The Mucosectom2 is composed of a non-conducting plastic shaft and a 2.5-mm cutting wire; the plastic shaft acts as an insulator and keeps an adequate distance between the muscle layers. On the other hand, the SB knife Jr. was designed as a small scissor forceps. As a grasping forceps, it is effective for performing ESD in the colon. Although both knives are especially ideal for submucosal dissection, how to use of these knives is completely different in the technical aspects in colon ESD. Therefore, it is also uncertain which knife is better for the trainee endoscopist to use for colorectal ESD. In our randomized trial, the results confirmed that there was no statistical significance advantage of the Mucosectom 2 knife over the SB knife Jr. Subgroup analyses were also performed among prespecified subgroups, and the differences were consistent, irrespective of lesion size and individual endoscopists. In fact, we demonstrated that the Mucosectom2 and the SB knife Jr. did not have statistically significantly different performances for colorectal ESD. The Mucosectom2 and the SB knife Jr. had comparable procedure times, with no increase in AEs when used by a trainee endoscopist. However, these results mean that there was no statistically significant difference, it does not mean that is clinically significant.

This study was limited by the use of only 2 trainee endoscopists in a single center. We planned to select 2 endoscopists with equivalent skill, but unexpectedly, there was a difference in treatment time. We speculate that the reasons for this include differences in preparation required for individual cases and differences in the individual endoscopist's learning curve. These endoscopists conducted most of the procedures under verbal advice by a senior endoscopist during some procedures. This advice may have affected the outcome of the study, but it was necessary to ensure that ESD was safely performed. In addition, a multicenter trial is required to further simplify these results. Many knives with similar functions are being developed. It is also necessary to compare all these knives in each organ for a more accurate approach.

From the results of this study, the Mucosectom2 and SB knife Jr. did not have significantly different performance in

- Table 2 Secondary end points.

\begin{tabular}{|l|l|l|l|}
\hline & Mucosectom2 group & SB knife group \\
\hline & $\mathbf{P}$ value \\
\hline En bloc resection (\%) & $15(94)$ & $\mathbf{2 0}$ \\
\hline Complete resection (\%) & $15(94)$ & $19(95)$ \\
\hline Self-completion (\%) & $15(94)$ & $20(100)$ \\
\hline Number of hemostatic therapies (time, mean) & 0.62 & 0.7 & 0.871 \\
\hline Perforation & $1(0.06)$ & $1(0.05)$ \\
\hline Injury to the muscularis propria & $3(0.19)$ & $6(0.3)$ \\
\hline Postoperative bleeding & $0(0)$ & 0.959 \\
\hline Cl, confidence interval; OR, odds ratio. & & 0.432 \\
\hline
\end{tabular}


terms of safe and reliable enhancement of colorectal ESD. In a previous small cohort study at our institution, we thought that colon ESD using the Mucosectom 2 might have been faster than the same procedure done using the SB knife Jr. However, in the current study, a few rectal lesions were present in the group in which the Mucosectom 2 was used, and there were many laterally spreading tumor non-granular (LST-NG) lesions, which often had fibrosis under the lesions. In previous studies, clinical and pathological factors, tumor size, and fibrosis were significant risks for perforation during colorectal ESD [11 - 13].

\section{Conclusions}

In the current study, we hypothesised that mean procedure time for colorectal ESD using the Mucosectom 2 knife would be $60 \pm 40 \mathrm{~min}$ and using the SB knife Jr. would be $100 \pm 40 \mathrm{~min}$ based on previous clinical data from our institution. However, this hypothesis proved to be a bit erroneous as we found that the Mucosectom 2 could not shorten the time as much as we had believed was possible. Therefore, in order to determine whether the Mucosectom2 significantly reduces treatment time over the SB knife Jr., a multicenter study with a large sample size is necessary. It is also more important to consider patient- and lesion-related factors rather than the performance of the knives.

\section{Acknowledgements}

The authors would like to acknowledge the reviewers for their helpful comments on this manuscript.

\section{Competing interests}

None

\section{References}

[1] Isomoto H, Shikuwa S, Yamaguchi $\mathrm{N}$ et al. Endoscopic sub-mucosal dissection for early gastric cancer: a large-scale feasibility study. Gut 2009; 58: $331-336$

[2] Soetikno RM, Gotoda T, Nakanishi Y et al. Endoscopic mucosal resection. Gastrointest Endosc 2003; 57: 567-579

[3] Saito Y, Uraoka T, Matsuda T et al. Endoscopic treatment of large superficial colorectal tumors: a case series of 200 endoscopic submucosal dissections. Gastrointest Endosc 2007; 66: 966 - 973

[4] Zhou PH, Yao LQ, Qin XY. Endoscopic submucosal dissection for colorectal epithelial neoplasm. Surg Endosc 2009; 23: 1546-1551

[5] Niimi K, Fujishiro M, Kodashima S et al. Long-term outcomes of endoscopic submucosal dissection for colorectal epithelial neoplasms. Endoscopy 2010; 42: 723-729

[6] Toyonaga T, Mani M, East JE et al. Endoscopic submucosal dissection cases in the esophagus, stomach, and colorectum: complication rates and long-term outcomes. Surg Endosc 2013; 27: 1000 - 1008

[7] Kawahara Y, Takenaka R, Okada H. Risk management to prevent perforation during endoscopic submucosal dissection. Dig Endosc 2007; 19: $9-13$

[8] Okamoto K, Kitamura S, Muguruma N et al. Mucosectom2-short blade for safe and efficient endoscopic submucosal dissection of colorectal tumors. Endoscopy 2013; 45: 928 - 930

[9] Homma K, Otaki Y, Sugawara M et al. Efficacy of novel SB knife Jr. examined in a multicenter study on colorectal endoscopic submucosal dissection. Dig Endosc 2012; 24: 117-120

[10] Kanzaki H, Ishihara R, Ohta T. Randomized study of two endo-knives for endoscopic submucosal dissection of esophageal cancer. Am J Gastroenterol 2013; 108: $1293-1298$

[11] Kim ES, Cho KBM, Park KS et al. Factors predictive of perforation during endoscopic submucosal dissection for the treatment of colorectal tumors. Endoscopy 2011; 43: 573-578

[12] Isomoto $H$, Nishiyama $H$, Yamaguchi $N$ et al. Clinicopathological factors associated with clinical outcomes of endoscopic submucosal dissection for colorectal epithelial neoplasms. Endoscopy 2009; 41: 679-683

[13] Hori K, Uraoka T, Harada K et al. Predictive factors for technically difficult endoscopic submucosal dissection in the colorectum. Endoscopy 2014; 46: $862-870$ 